\title{
Study of the prospects for expanding the range of collectors in the flotation of fluorite from technogenic raw materials
}

\author{
Olga Voronova $^{1 *}$ and Lidia Kiyenko ${ }^{1}$ \\ ${ }^{1}$ Mining Institute FEB RAS, 51 Turgenev st., Khabarovsk, 680000, Russia
}

\begin{abstract}
The results of studies on the development of a technology for the extraction of fluorite concentrates from finely disseminated refractory technogenic raw materials from Primorsky deposits were presented. The account of the technological features of the stale tailings of the concentration plant of Yaroslavkaya Mining Company has been given. The necessity of fine grinding of the material and careful selection of reagent compositions providing the required flotation selectivity has been substantiated. The fundamental possibility of obtaining fluorite concentrates containing $\mathrm{CaF}_{2}$ up to $94 \%$ and more using several samples of collectors from the group of fatty acids has been established. Fatty acids of tall oil produced by Ust-Ilimsk timber processing complex and a mixture of fatty acids produced in India, branded MASOIL 1880, provide a sufficient level of flotation selectivity. The recovery of fluorite in an open enrichment cycle according to the scheme with seven cleanings of the foam product can be $61.85-63.84 \%$.

The use of collectors compositions promotes an increase in the selectivity of the adsorption of reagents, which is accompanied by an increase in the selectivity of their action in comparison with the results obtained with the dosage of certain brands of the tested reagents into the flotation process. The extraction of fluorite into a concentrate obtained using a combination of tall oil and MASOIL-S fatty acids in a 1:1 ratio was $59.55-66.27 \%$ with a content of $95.6-94.23 \% \mathrm{CaF}_{2}$ in it, respectively.
\end{abstract}

Keywords: technogenic raw materials, fluorite, calcite, silicates, fine grinding, fatty acids, hydrocarbon radical, collectors compositions.

\section{Introduction}

The basis for achieving high selectivity in the flotation of refractory ores is a rational selection of reagent compositions. When enriching calcium-containing mineral raw materials, including fluorite ores, carboxylic compounds of various nature are used as collectors. The most effective of them are mixtures of unsaturated fatty acids, the range of which is quite wide on the Russian and world markets. For ores containing minerals similar in flotation properties, a particularly careful analysis of the characteristics of the collectors used and their combinations is required. The development of a technology for extracting

${ }^{*}$ Corresponding author: olya-vo@mail.ru 
fluorite from complex, including technogenic, raw materials requires an analysis of the technological properties of reagents with different structures of hydrocarbon radicals, which makes it possible to assess their adsorption characteristics under conditions of a liquid phase of pulp that is non-uniform in salt composition and physicochemical properties.

The ores available for mining in the Voznesensky ore region, which are the raw materials base of Yaroslavkaya Mining Company (YaMC), contain no more than 26-29\% $\mathrm{CaF}_{2}$ and up to $20-25 \% \mathrm{CaCO}_{3}$. Carbonate modulus value $\left(M_{\kappa}=\alpha_{\mathrm{CaF}_{2}} / \alpha_{\mathrm{CaCO}_{3}}\right)$, largely determining the washability of calcium-containing raw materials, is $1.05-1.45$. According to the available data, the volume of tailings from the processing of fluorite ores stored in the tailings dump of the enterprise is estimated at 30 million tons or more. The content of fluorite in them ranges from $13-23 \%$, calcite - not more than $12-14 \%$. The average value of the carbonate modulus is 1.4-1.6. According to preliminary estimates, technogenic raw materials of this composition may represent a promising object for recycling.

All ores of the Voznesensky ore region (VOR), which are the primary raw material sources of YaMC, are classified as refractory. The main reasons include a very fine mutual intergrowth of mineral phases and the presence of calcium-containing components similar in flotation properties $[1,2]$. In technogenic tailings, fluorite is represented by the most problematic grains that were not recovered at the stage of primary enrichment, due to the presence on their surface of a significant amount of thin surface coatings in the form of silicate minerals, as well as slime-like particles. The technological scheme for the enrichment of such material should combine operations that ensure the maximum possible separation of components, as well as neutralization of excess sludge, residues of reagents from the primary processing stage and products of secondary interactions formed as a result of storage $[3,4]$.

\section{Materials and Methods}

Studies of the possibility of obtaining fluorite concentrates from technogenic raw materials were carried out using a tailings sample taken from the tailings dump of the YaMC concentrating plant. A chemical analysis has established the following contents of the main components: $\mathrm{CaF}_{2}-19,0 \%, \mathrm{CaCO}_{3}-12,9 \%, \mathrm{SiO}_{2}-31,2 \%, \mathrm{Zn}-0,37 \%$. The evaluation of the particle size distribution of the sample showed that the content of grains less than 0.044 $\mathrm{mm}$ in size, which is how the grinding size is monitored at the enterprise, is $51-53 \%$.

The YaMC facility is currently suspended for renovation. During almost the entire period of operation, the company produced concentrates of the FF-90 grade and, in a smaller amount - those of the FF-92 grade, containing, respectively, 90 and $92 \% \mathrm{CaF}_{2}$. Today, due to the increased demand in the domestic and world markets for high-purity concentrates, the issue of improving their quality has become acute. It is hardly possible to obtain high-grade products, corresponding in their composition to the FF-95 and FF-97 grades, with satisfactory recovery rates, from such low-quality raw materials. However, taking into the account planned reconstruction of technological lines of cryolite production, the content of $\mathrm{CaF}_{2}$ lower than $93-94 \%$ is not suitable for the end-users.

One of the most important conditions for obtaining the most pure concentrates is the mechanical treatment of the material, which ensures the fullest possible release of fluorite grains. In this regard, a series of experiments was carried out at the initial stage of research to identify the influence of the degree of grinding of technogenic tailings on flotation parameters. Satisfactory technological parameters were obtained by grinding to a content of the controlled class $(-0.044 \mathrm{~mm})$ of $92-95 \%$. With the content of $\mathrm{CaF}_{2}$ in the concentrates amounting to $93.28-94.14 \%$, the fluorite extraction was $60.26-61.75 \%$. A further increase in the degree of grinding can lead to a decrease in technological parameters $[5,6]$. 
The reagent regime of the experiments carried out at the first stage was based on the use of tall oil fatty acids (TOFA) as a collector, being a by-product of the wood chemical industry, in combination with a complex modifier based on ammonium fluoride [7]. TOFA are represented by a mixture of oleic (up to $26 \%$ ), linoleic and linolenic acids (total of 52$65 \%$ ); they proven to have a good track record in the authors' many years of research; a large industrial testing program has been implemented with the use of this collector. The results obtained allowed the YaMC enrichment factory to process the lean refractory ores with satisfactory results [8]. Periodic shifts to a use of other collectors (most often, technical soaps of various brands) were associated with a shortage of TOFA products in the Russian market.

\section{Results and Discussion}

A series of experiments on the enrichment of technogenic tailings using an open flotation circuit and TOFA as a collector has shown the possibility of stable production of fluorite concentrates containing $93 \% \mathrm{CaF}_{2}$ and higher with fluorite recovery of no more than 58 $62 \%$. Reducing the $\mathrm{CaF}_{2}$ content by $1-1.5 \%$ allows increasing the recovery by $5-8 \%$.

For refractory secondary raw materials, the results obtained can be assessed as satisfactory. Meantime, continuously increasing requirements for the quality of fluorite concentrates and, at the same time, the shortage of highly selective fatty acids in the Russian market suggest the need to assess the prospects for expanding the range of efficient collectors that provide the highest level of selection of hard-to-separate minerals.

Studies on the flotation of fluorite from technogenic tailings using collectors of various compositions were carried out according to an open-cycle scheme, including main flotation and up to eight cleanings of rough fluorite concentrate. In addition to the use of TOFA, the effects of industrial soap produced by Ussuriysky Oil and Fat Plant, oleic acid B-115 of two brands of fatty acids made in India and fatty acids FX-6 made in China were studied. The MAS Group of Companies selling fatty acids made by LLC MAS Albion carried out a marketing research and identified a group of fatty acid collectors that are economically promising for use in flotation. Indian samples MASOIL-S, MASOIL-1880, and Chinese FX-6 were tested earlier on scheelite ores of Primorsky deposits [9]. In terms of the spectrum of fatty acids, the samples of Indian brands are quite close to TOFA. The MASOIL-1880 brand is the most enriched in linolenic acid, which has three double bonds in the hydrocarbon radical. It is known that collectors from the group of fatty acids, which have two or three unsaturated bonds in the structure of the hydrocarbon radical, differ [1012], mainly by high selective properties, especially in fine pulps.

Table 1 shows the characteristics of the collectors used in the experiments. The composition of the industrial soap made by Ussuriysky Oil and Fat Plant is not constant. The portion of each of its constituent saponified higher fatty acid depends on the types of raw materials.

The use of industrial soap by the YaMC enrichment factory has been practiced for a long time. During the crisis period, the low price and the proximity of the manufacturer $(\sim 50 \mathrm{~km})$ were important arguments for its use. The results of comparative experiments on the flotation of fluorite from technogenic tailings using various fatty acids as collectors are presented in Table 2 . 
Table 1. Composition of fatty acid collectors

\begin{tabular}{|l|c|c|c|c|c|}
\hline $\begin{array}{c}\text { Name, carbonic } \\
\text { composition }\end{array}$ & $\begin{array}{c}\text { Oleic acid } \\
\text { B-115 }\end{array}$ & TOFA & $\begin{array}{c}\text { MASOIL-S } \\
\text { (India) }\end{array}$ & $\begin{array}{c}\text { MASOIL-1880 } \\
\text { (India) }\end{array}$ & FX-6 \\
\hline Myristic $\mathrm{C}_{14: 0^{*}}$ & - & - & 0.10 & 5.18 & - \\
\hline Palmitic $\mathrm{C}_{16: 0}$ & 5.7 & $3.9-9.1$ & 3.76 & - & 6 \\
\hline Stearic $\mathrm{C}_{18: 0}$ & 5.6 & $2.2-4.4$ & 5.19 & 2.62 & 3 \\
\hline Oleic $\mathrm{C}_{18: 1}$ & 58.9 & $10-26.6$ & 35.78 & 21.94 & 50 \\
\hline Linoleic $\mathrm{C}_{18: 2}$ & 26.6 & $36.1-54.7$ & 27.52 & 33.52 & 24 \\
\hline Linolenic $\mathrm{C}_{18: 3}$ & 1.3 & $5-15.7$ & 16.09 & 21.58 & - \\
\hline Arachidic $\mathrm{C}_{20: 0}$ & 0.5 & - & 10.75 & 1.12 & - \\
\hline Gadoleinone $\mathrm{C}_{20: 1}$ & 0.1 & - & - & 10.81 & - \\
\hline Resin & - & Under 2 & - & - & - \\
\hline $\begin{array}{l}\text { Iodine number } \\
\left(\mathrm{gI}_{2} / 100 \mathrm{~g}\right)\end{array}$ & 115 & - & 140.0 & 135.2 & 120 \\
\hline $\mathrm{N}_{2} \mathrm{Th}$ & & & & & \\
\hline
\end{tabular}

Note. The carbon composition of acids indicates the number of carbon atoms in the molecule and the number of double bonds

Table 2. Fluorite flotation parameters when using various branded collectors

\begin{tabular}{|c|c|c|c|c|c|c|}
\hline \multirow{2}{*}{ Test } & \multirow{2}{*}{ Product } & \multirow{2}{*}{$\begin{array}{c}\text { Yield, } \\
\%\end{array}$} & \multicolumn{2}{|c|}{ Content, $\%$} & \multirow{2}{*}{$\begin{array}{c}\text { Extracted } \\
\mathrm{CaF}_{2}, \%\end{array}$} & \multirow{2}{*}{ Collector } \\
\hline & & & $\mathrm{CaF}_{2}$ & $\mathrm{CaCO}_{3}$ & & \\
\hline \multirow{4}{*}{1} & Concentrate of $8^{\text {th }}$ cleaning & 11.95 & 94.92 & 0.49 & 59.84 & \multirow{4}{*}{ TOFA } \\
\hline & Concentrate of $7^{\text {th }}$ cleaning & 12.83 & 94.35 & 0.66 & 63.84 & \\
\hline & Concentrate of $6^{\text {th }}$ cleaning & 13.68 & 93.43 & 1.07 & 67.41 & \\
\hline & Feed & 100 & 18.96 & 12.87 & 100 & \\
\hline \multirow{4}{*}{2} & Concentrate of $8^{\text {th }}$ cleaning & 11.53 & 94.82 & 0.59 & 57.53 & \multirow{4}{*}{$F X-6$} \\
\hline & Concentrate of $7^{\text {th }}$ cleaning & 12.29 & 94.13 & 0.82 & 60.87 & \\
\hline & Concentrate of $6^{\text {th }}$ cleaning & 13.10 & 93.13 & 1.29 & 64.18 & \\
\hline & Feed & 100 & 19.01 & 12.9 & 100 & \\
\hline \multirow{4}{*}{3} & Concentrate of $8^{\text {th }}$ cleaning & 11.84 & 94.59 & 0.55 & 58.85 & \multirow{4}{*}{$\begin{array}{c}\text { MASOIL- } \\
1880\end{array}$} \\
\hline & Concentrate of $7^{\text {th }}$ cleaning & 12.49 & 94.23 & 0.74 & 61.85 & \\
\hline & Concentrate of $6^{\text {th }}$ cleaning & 13.18 & 93.73 & 0.99 & 64.92 & \\
\hline & Feed & 100 & 19.03 & 12.98 & 100 & \\
\hline \multirow{4}{*}{4} & Concentrate of $8^{\text {th }}$ cleaning & 12.92 & 93.74 & 0.79 & 64.07 & \multirow{4}{*}{ MASOIL-S } \\
\hline & Concentrate of $7^{\text {th }}$ cleaning & 13.62 & 92.86 & 1.27 & 66.89 & \\
\hline & Concentrate of $6^{\text {th }}$ cleaning & 14.24 & 91.76 & 2.00 & 69.09 & \\
\hline & Feed & 100 & 18.91 & 12.92 & 100 & \\
\hline \multirow{4}{*}{5} & Concentrate of $8^{\text {th }}$ cleaning & 10.51 & 95.5 & 0.69 & 52.89 & \multirow{4}{*}{$\begin{array}{l}\text { Industrial } \\
\text { soap }\end{array}$} \\
\hline & Concentrate of $7^{\text {th }}$ cleaning & 11.34 & 94.43 & 1.20 & 56.43 & \\
\hline & Concentrate of $6^{\text {th }}$ cleaning & 12.27 & 92.48 & 2.46 & 59.82 & \\
\hline & Feed & 100 & 18.97 & 13.03 & 100 & \\
\hline \multirow{4}{*}{6} & Concentrate of $8^{\text {th }}$ cleaning & 13.68 & 92.04 & 1.39 & 66.44 & \multirow{4}{*}{$\begin{array}{c}\text { Oleic acid } \\
\quad B-115\end{array}$} \\
\hline & Concentrate of $7^{\text {th }}$ cleaning & 13.92 & 91.56 & 1.58 & 67.36 & \\
\hline & Concentrate of $6^{\text {th }}$ cleaning & 14.21 & 90.85 & 2.12 & 68.12 & \\
\hline & Feed & 100 & 18.95 & 13.25 & 100 & \\
\hline
\end{tabular}

Concentrates containing over $93 \% \mathrm{CaF}_{2}$ were obtained in experiments using TOFA, industrial soap, FX-6, as well as MASOIL-1880 fatty acids manufactured in India. The highest quality concentrates were obtained in experiments with industrial soap and TOFA (95.5-94.92\%, respectively). As evidenced by the above data, the extraction of fluorite in experiments using industrial soap is significantly lower $-52.89 \%$; a dosage of TOFA in the process allows extracting into concentrates containing $94.92-94.35 \% \mathrm{CaF}_{2}$ of up to $63.84 \%$ 
$\mathrm{CaF}_{2}$. Concentrates of slightly lower quality were obtained with a close extraction of fluorite with the use of oleic acid and fatty acids MASOIL-S (India) in the process. The use of the Indian collector MASOIL-1880 provides a high-quality concentrate containing $93.73 \% \mathrm{CaF}_{2}$ with a sufficiently high fluorite recovery.

In addition to testing collectors of various compositions in a monovariant during the flotation of technogenictailings, the study of the effect of carboxylic compounds on the technology was carried out. Studies of the efficiency of using TOFA in flotation in combination with other fatty acid collectors, the composition of which is represented by a spectrum of compounds differing in the degree of saturation, length, and structure of hydrocarbon radicals, were carried out by the authors earlier on VOR ores $[13,14]$. As a result, it has been found that broadening the range of fatty acids in the composition can result in higher enrichment rates while generally lowering the collectors consumption.

The data of experiments on the extraction of fluorite from technogenic tailings using various combinations of collectors are shown in Fig. 1.
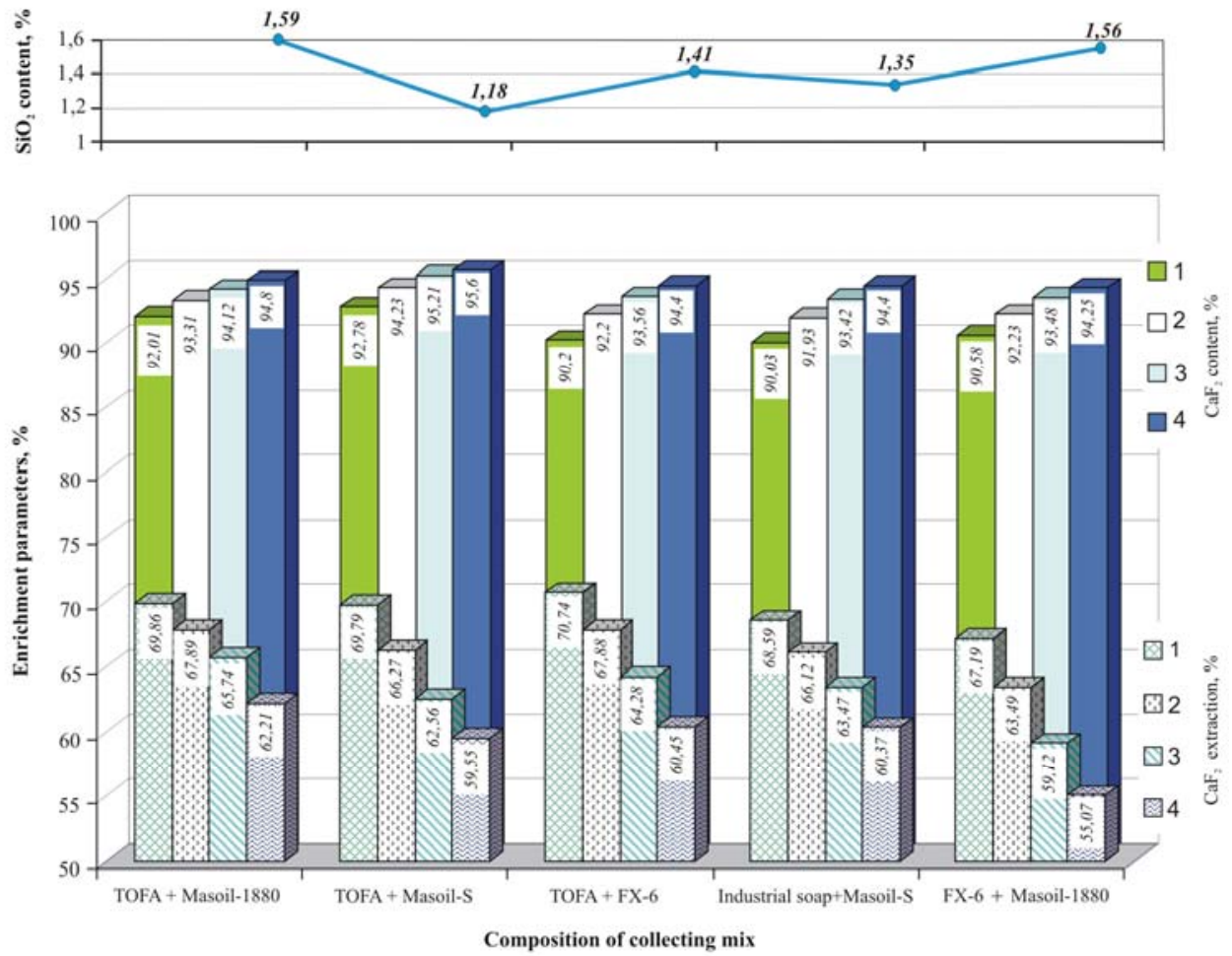

Fig. 1. Technological indicators of fluorite extraction in to concentrates of various quality using collective mixtures: 1 -concentrate of the fifth cleaning; 2 -concentrate of the sixth cleaning; 3 concentrate of the seventh cleaning; 4 -concentrate of the eighth cleaning

The analysis of the results obtained shows that the dosage of various collector compositions into the flotation process allows, in general, to significantly increase their adsorption activity and selective properties. The highest effect was obtained during flotation using TOFA compositions with Indian reagents MASOIL-1880 and MASOIL-S. The concentrates obtained after eight cleanings contain $94.8-95.6 \% \mathrm{CaF}_{2}$, with fluorite recovery $62.21-59.55 \%$. At the same time, the use of TOFA mixed with MASOIL-S makes it possible to obtain a high-quality concentrate with $\mathrm{a} \mathrm{CaF}_{2}$ content of $95.21 \%$ and a fluorite recovery of $62.56 \%$ after seven cleaning operations. The extraction of fluorite into a concentrate with a content of $94.23 \%$, obtained as a result of six cleanings of the foam 
product, amounts to $66.27 \%$. In addition, the analysis for the content of silicon dioxide, which is a strictly limited harmful impurity in fluorite concentrates, showed that during flotation using combinations of collectors, there is a tendency to some decrease in its content in the final concentrates. Thus, the use of TOFA in combination with MASOIL-S makes it possible to obtain a concentrate containing $1.18 \% \mathrm{SiO}_{2}$, a composition of MASOIL-S and industrial soap $-1.35 \%$, respectively. For refractory secondary raw materials, obtained parameters can be assessed as rather high. Flotation using other combinations of reagents (FX-6 with TOFA, MASOIL-1880, industrial soap with MASOIL-S) is also efficient. At the same time, the results using collective compositions have higher values than when using the corresponding brands of reagents in the mono version.

\section{Conclusions}

The studies carried out made it possible to assess the effectiveness of the actions of various collectors from the group of fatty acids and their compositions in the process of flotation of fluorite from technogenic raw materials.

The possibility of obtaining concentrates containing $\mathrm{CaF}_{2}$ over $94 \%$ using TOFA, industrial soap produced by Ussuriysky Oil and Fat Plant, MASOIL-1880 fatty acids made in India, FX-6 from Chinese manufacturers has been shown. The highest recovery rates are provided by TOFA and MASOIL- 1880 .

It was found that the use of collector compositions provides higher technological indicators in comparison with the use of each of the tested brands in mono version. The extraction of fluorite into the concentrate obtained using the combination of TOFA + MASOIL-S in a 1:1 ratio was $59.55-66.27 \%$ with a content of $95.6-94.23 \% \mathrm{CaF}_{2}$, respectively, which is noticeably higher by the quality of concentrates, as well as by the extraction of fluorite in them.

\section{REFERENCES}

1. V.E. Pavlov, P.F. Kugot, Mining Journal, 9, 25 (2000)

2. L.A. Samatova, L.A. Kiyenko, O.V. Voronova, L.N. Plyusnina, Mining Information and Analytical Bulletin, Far East, 274 (2005) 1964)

3. M.A. Eigeles, Fundamentals of flotation of non-sulfide minerals, (Moscow: Nedra,

4. I. Jovanovic, I. Miljanovic, Modeling of flotation processes by classical mathematical methods - a review Archives of Mining Sciences, 60, № 4, 905 (2015)

5. V.I. Klassen, D.I. Nedogorov, I.Kh. Deberdeyev, Slimes in the flotation process, (Moscow: Nedra, 1969)

6. L.A. Kienko, O.V. Voronova, Physical and technical issues of minerals development, 1, $176(2014)$

7. L.A. Kiyenko, O.V. Voronova, Patent No. 2646268 RF. Method of concentration of carbonate-fluorite ores, applicant and patent holder is the Mining Institute of the FarEastern Branch of the RAS; applied 12.04.2017; published02.03.2018, BulletinNo. 7 (2018)

8. L.A. Kiyenko, L.A. Samatova, O.V. Voronova, Mining Journal,12, 63 (2013)

9. E.D. Shepeta, L.A. Samatova, Innovative processes of complex and deep processing of mineral raw materials, (Plaksin readings, 2013)

10. V.A. Glembotskiy, Physical chemistry of floatation processes, (Moscow: Nedra, 1972) 
11. K.C. Runge, J.P Franzidis, E.V. Manlapig, Structuring a flotation model for robust prediction of flotation circuit performance XXII International Mineral Processing Congress, Cape Town,973 ( 2003)

12. M. Polat, S. Chander, First-order flotation kinetics models and methods for estimation of the true distribution of flotation rate constants, International Journal of Mineral Processing, 58, 166 (2000)

13. L.A. Kiyenko, L. A. Samatova, O. V. Voronova, L. N. Plyusnina, Enrichment of ores, 3, 25 (2009)

14. A.A. Abramov Flotation, Collecting reagents, 656 (Moscow: Gornaya kniga, 2012) 